\title{
Role of partial splenic artery embolization in corpuscular correction in cirrhotic patients before anti-viral therapy: a recent update study among Egyptian patients
}

\author{
Mostafa Mohamed Mostafa Elian, Mohamed Ahmed A. Samea and Nasr Mohamed M. Osman * (D)
}

\begin{abstract}
Background: To evaluate the role of partial splenic artery embolization in corpuscular correction in cirrhotic patients.

Results: Bleeding tendency was experienced in two thirds of patients (66.7\%) and anemia in 63.3\%. Splenic size ranged from 14.3 to $22 \mathrm{~cm}$. PV diameter ranged from 11 to $18 \mathrm{~mm}$. The mean platelet at the pre-operative laboratory was $34.9 \pm 10.3 \times 10^{3}$, corrected to $137.6 \pm 37.1 \times 10^{3}$ within 1 month follow-up, and then $140 \times 10^{3}$ after 6 months. The mean of RBCs was $3.6 \pm 0.3 \times 10^{6}$, then $4 \pm 0.5 \times 10^{6}$ at 1 month follow-up period. WBCs showed correction at the early post-operative period, $3.3 \pm 0.4 \times 10^{3}$, compared to $5.4 \pm 1.4 \times 10^{3}$ at 1 month. Reduction in splenic size was achieved by 3-6 months. All patients (100\%) had post-embolization syndrome. Gelfoam was used in 20 patients, PVA was used in 5 patients, and microspheres were used in 5 patients. Antiviral treatment regimen was started after an adequate rise in corpuscular counts in all patients.

Conclusion: Partial splenic artery embolization is an effective alternative method to surgery in treatment of hypersplenism particularly in cirrhotic patients prepared for antiviral treatment with correction of the associated thrombocytopenia.
\end{abstract}

Keywords: Hypersplenism, Transcatheter embolization of splenic parenchyma, Partial splenic embolization (PSE)

\section{Background}

Hypersplenism refers to a clinical syndrome characterized by splenomegaly, anemia, leukopenia, thrombocytopenia, and compensatory bone marrow hyperplasia [1]. Hypersplenism represents increased pooling and destruction of the corpuscular elements of the blood, mainly platelets by the enlarged spleen [2], which is seen in many disorders, including cirrhosis with portal hypertension [3], hematologic abnormalities such as idiopathic thrombocytopenic purpura, thalassemia major, and hereditary spherocytosis, and diffuse splenic infiltration from primary malignancies such as leukemia and lymphoma [4]. The

\footnotetext{
* Correspondence: nasrosman_7@yahoo.com

Diagnostic and Interventional Radiology Department, Faculty of Medicine, Minia University, Cairo-Aswan Road Way, Minya 51619, Egypt
}

frequency of hypersplenism in patients with chronic liver disease varies between 30 and 70\% [5]. Total splenectomy may be an effective treatment for hypersplenism, but it impairs the body's ability to produce antibodies against encapsulated microorganisms and predisposes patients to sepsis; also, lifelong vaccination may be needed postsurgery [3].

Since 1973, splenic artery embolization for hypersplenism was usually performed. Initially, total aggressive embolization of the splenic parenchyma was performed, but severe complications, such as splenic abscess, overwhelming pneumonia, sepsis, hematoma and bleeding, pancreatic infarction, and even death, limited the usage of this technique. Since then, many authors start to practice incomplete or partial splenic arterial embolization, in
Springer Open
(๑) The Author(s). 2020 Open Access This article is licensed under a Creative Commons Attribution 4.0 International License, which permits use, sharing, adaptation, distribution and reproduction in any medium or format, as long as you give appropriate credit to the original author(s) and the source, provide a link to the Creative Commons licence, and indicate if changes were made. The images or other third party material in this article are included in the article's Creative Commons licence, unless indicated otherwise in a credit line to the material. If material is not included in the article's Creative Commons licence and your intended use is not permitted by statutory regulation or exceeds the permitted use, you will need to obtain permission directly from the copyright holder. To view a copy of this licence, visit http://creativecommons.org/licenses/by/4.0/. 
which a portion of the splenic parenchyma is left viable to preserve the splenic tissue for immunologic function allowing defense against infections $[3,6]$.

Since then, transcatheter embolization of splenic parenchyma is often widely used for management of hypersplenism [2] and has been thought to be an effective safe alternative to splenectomy $[7,8]$ with subsequent improvement of anemia, leukopenia, and thrombocytopenia [9] especially in patients with comorbidity, like liver cirrhosis. This study aimed to evaluate the role of partial splenic artery embolization in correcting thrombocytopenia in cirrhotic patients with clinical manifestations of hypersplenism.

\section{Methods}

\section{Patients}

The study was approved by the local institutional ethics and review committee of our university. Informed consent was obtained from all participants. This study included 30 patients which presented with clinical manifestations of hypersplenism secondary to chronic liver disease; all patients underwent partial splenic embolization to correct thrombocytopenia. All patients were proved clinically and in the laboratory. All were referred from the hepatology departments and outpatient clinics of university hospitals. The study time frame was from January 2015 to December 2017.

All patients were subjected to the following.

\section{Clinical history taking}

Clinical history taking includes the following:

- Relevant history, like bilharziasis with previous antibilharzial therapy, blood transfusion, and other risk factors that can contribute in the determination of the etiology of liver disease

- History of blood disease (anemia or leukemia) or bleeding tendency

- Presence of portal hypertension, hematemesis, or melena

- History of chronic liver disease or liver cell failure or precoma

\section{Laboratory investigations}

Laboratory investigations include the following:

- Complete blood picture with stress on platelet count

- Antiplatelet antibodies

- Liver profile including liver enzymes (ALT and AST), total and direct bilirubin, and serum albumin

- Prothrombin time, concentration, and INR

- Viral markers (HBsAg and HCVAbs)

- Renal function tests (serum creatinine and blood urea)
- Bone marrow aspiration to exclude bone marrow causes of thrombocytopenia

\section{Abdominal ultrasonography with color Doppler study}

Color Doppler US examination was done by GE logic P5 and P8, and all patients kept fasting overnight prior to the ultrasonography examination.

Spleen: Size, echogenicity, presence of focal lesions, splenic vein diameter and patency as well as duplex study, with stress upon the splenic maximal length, SV diameter, and blood flow velocity within.

Liver: Size, surface, echogenicity, presence of focal lesions and portal vein ultrasonographic, and duplex examination.

Portal trunk was scanned longitudinally. The portal vein diameter was measured directly about $1.5-2.5 \mathrm{~cm}$ before the bifurcation to the right and left branches. The portal flow velocity (PFV) in centimeters per second $(\mathrm{cm} / \mathrm{s})$ was averaged by Doppler traces of 2-3 cardiac cycles, as well as direction of portal blood flow; the cross-sectional area of PV was also measured with the calculation of congestion index as well as the presence of ascites and collaterals.

\section{Child-Pugh classifications of the patients in the study}

In this study, most of the patients (25 patients) were Child-P A classification with good general condition and good liver function, with no ascites or encephalopathy.

Only few cases (5 cases) were early Child B classification (B7) and were embolized to save the patient's life; however, no major complications were noted within.

\section{Inclusion criteria}

- Cases of hypersplenism secondary to chronic liver disease

- Platelet count less than $(50,000 \backslash \mu \mathrm{L})$

- Child-P classification A or early B

- Good general performance status

- Absence of ascites

\section{Exclusion criteria}

- Child-Pugh C classification

- Moderate and marked ascites

- Portal or splenic vein thrombosis or reversed flow of portal vein on color Doppler US

- Allergy to contrast media

- Aortoiliac or bilateral femoral artery occlusion

- Hypocellular bone marrow 
Table 1 Demographic data of the study group

\begin{tabular}{lccc}
\hline $\begin{array}{l}\text { Descriptive } \\
\text { statistics }(\boldsymbol{n}= \\
30)\end{array}$ & Range & Mean & \pm SD \\
\hline Age in (years) & $(25-61)$ & 44.8 & \pm 10.7 \\
\hline
\end{tabular}

\section{Pre-embolization and patient preparation}

The benefits and potential risks of splenic embolization were explained to each patient, and informed consent was obtained.

The participants were asked to fast for $12 \mathrm{~h}$. All patients received broad spectrum antibiotics prophylaxis 6 $\mathrm{h}$ before embolization (which consisted of 3rd generation cephalosporins, combined ampicillin-sulbactam and metronidazole). Good sterilization of the patient was routinely done.

\section{Embolization protocol}

The patient lies supine in the angiography suite, both groins were prepped by betadine, and percutaneous femoral puncture was performed using cutaneous and perivascular local anesthesia infiltration to induce arterial vasculoplegia and to reduce pain during and postprocedure.

Seldinger's technique was then used for the $6 \mathrm{~F}$ femoral sheath insertion. Unilateral femoral artery approach was usually used for partial splenic artery embolization technique (used almost in all patients, only one patient underwent transradial approach).

To catheterize the celiac trunk, a 0.035 hydrophilic guide wire (Radiofocus Inc.) and 5 Fr Cobra catheter (Angiodynamic/Cordis Inc.) were used. Splenic artery was then selectively catheterized; by advancing the catheter over the guidewire, preliminary splenic arteriography was obtained to determine the exact splenic size, configuration of the splenic artery, and location of the pancreatic branches. The catheter was then advanced forward as distal as possible, so that its tip lies distal to the pancreatic branches. Very particular attention was paid to the dorsal pancreatic artery to avoid any potential reflux of the embolic agents.

\section{Approaches for partial splenic artery embolization}

The first approach was non-selective approach that was used in the majority of cases (25 patients); it was performed when the splenic artery was tortuous and difficult to selectively catheterize distal splenic branches. In these cases, the catheter tip was positioned more proximally in the main splenic artery as distal as we can, beyond the last major pancreatic branch.

The second approach used was selective approach (done in five patients); in this approach, few distal branches of the splenic artery are selectively catheterized using micro-catheter to reach this position (2.4-3 Fr Renegade ${ }^{\oplus} \mathrm{Hi} \mathrm{Flo}^{\mathrm{TM}}$ Microcatheter (Boston Scientific, Natick, MA) with a 0.027-in. inner diameter, and embolization is performed to achieve complete stasis in these in the targeted branches.

Embolic particles were mixed with the contrast material and injected slowly until stasis, with the parenchymal blush produced.

Either temporary (Gelfoam) or permanent occluding materials (Microspheres and PVA) were used as embolizing material in the study; Gelfoam particles were the most used embolizing materials in our study, used in 20 patients, while the permanent occluding materials were used only in 10 patients (PVA or Embosphere, Boston Scientific); 355- to $500-\mu \mathrm{m}$ particles were usually used with size of up to 500 to $700 \mu \mathrm{m}$ for splenic artery. These particles were mixed

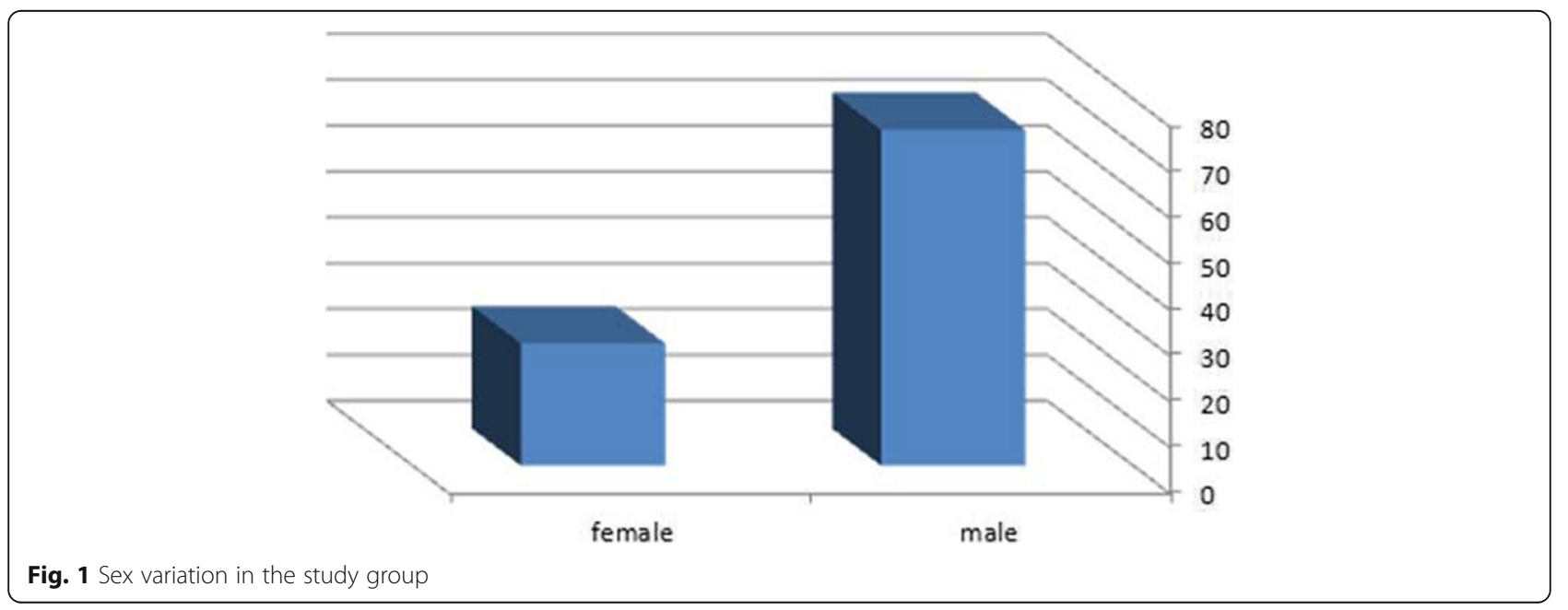


Table 2 Pre-embolization relevant US findings

\begin{tabular}{ll}
\hline & Descriptive statistics $(\boldsymbol{n}=30)$ \\
\hline Liver status & $25(83.3 \%)$ \\
Cirrhotic & $5(16.7 \%)$ \\
Non cirrhotic & \\
Splenic size (cm) & $14.3-22 \mathrm{~cm}$ \\
Range & $17.8 \pm 2.1 \mathrm{~cm}$ \\
$\quad$ Mean \pm SD & \\
PV diameter $(\mathbf{m m})$ & $11-18 \mathrm{~mm}$ \\
$\quad$ Range & $14.7 \pm 1.9 \mathrm{~mm}$ \\
$\quad$ Mean \pm SD & \\
Ascites & $27(90 \%)$ \\
No & $3(10 \%)$ \\
Yes & \\
Varices & $25(83.3 \%)$ \\
No & $5(16.7 \%)$ \\
Yes &
\end{tabular}

with $80 \mathrm{~g}$ gentamicin and contrast material, and the mixture was injected slowly. The endpoint of embolization was usually determined when angiography showed that an estimated $50-70 \%$ of the splenic parenchyma was successfully embolized, evaluated during the parenchymal phase of serial arteriograms, and then the procedure was terminated.

\section{Post-embolization regimen}

All patients were admitted before the procedure and remained in the hospital until the post-embolization syndrome or any significant complications disappear. Analgesic management was followed routinely and combined with an anti-inflammatory agent. Supportive care includes appropriate hydro-electrolytic infusions, broad spectrum antibiotics (3rd generation cephalosporins, amoxicillin-clavulanate (3 g/day) and ofloxacin $(400 \mathrm{mg} /$ day) for at least 7 days after the procedure, and analgesics (paracetamol and even morphine if needed). The clinical assessment was performed by the patient's physician at discharge and consultations at 1 month, 3 months, and 6 months after the procedure.

Table 3 Laboratory response based on platelet count

\begin{tabular}{llll}
\hline Platelet count before and after embolization $\left(\times 10^{\mathbf{3}}\right)$ & \\
\hline & Range & Mean \pm SD & $\boldsymbol{P}$ value \\
\hline Pre-embolization & $15-50$ & $34.9 \pm 10.3$ & \\
1 month post-embolization & $70-200$ & $137.6 \pm 37.1$ & $<0.001^{*}$ \\
3 months post-embolization & $110-180$ & $145 \pm 35$ & $<0.001^{*}$ \\
6 months post-embolization & $80-175$ & $137.7 \pm 26.3$ & $<0.001^{*}$ \\
\hline
\end{tabular}

Table 4 Laboratory response based on RBC count

\begin{tabular}{llll}
\hline RBC count before and after embolization $\left(\times 10^{\mathbf{6}}\right)$ & \\
\hline & Range & Mean \pm SD & $\boldsymbol{P}$ value \\
\hline Pre-embolization & $3-4.3$ & $3.6 \pm 0.3$ & \\
1 month post-embolization & $3.2-5$ & $4 \pm 0.5$ & $<0.001^{*}$ \\
3 months post-embolization & $3.5-5$ & $4.3 \pm 0.4$ & $<0.001^{*}$ \\
6 months post-embolization & $3.5-5.5$ & $4.4 \pm 0.5$ & $<0.001^{*}$ \\
\hline
\end{tabular}

\section{Follow-up}

The post-procedure result and follow-up was analyzed from the medical and radiologic files.

The laboratory tests included CBC stressing on platelet count and liver and renal functions before discharge, and then $\mathrm{CBC}$ was repeated at 1,3 , and 6 months after embolization.

Morphologic verification by CT examination took place 1 month after embolization to assess the volume of the infarcted areas and detect any post-embolization complications. In the follow-up visits, $\mathrm{CBC}$ and abdominal ultrasonography were done routinely.

\section{Statistical test}

The data were coded, entered, and processed on an IBM-PC compatible computer using SPSS (version 19).

\section{Results}

This study included 30 patients which presented with clinical manifestations of hypersplenism secondary to chronic liver disease; all patients were proved clinically and in the laboratory as they were on the regimen for anti-viral therapy. Eight patients were females, and the rest were males (Table 1, Fig. 1).

Thrombocytopenia and bleeding tendency were the most distressing symptom that was experienced in two thirds of patients (66.7\%) and anemia and its associated manifestations in 19 out of 30 patients (63.3\%). Dull aching left hypochondrial pain elicited in 15 out of 30 patients (50\%).

The splenic size of the patients included ranged from 14.3 to $22 \mathrm{~cm}$ (mean $17.8 \pm 2.1 \mathrm{~cm}$ ). Portal vein diameter ranged from 11 to $18 \mathrm{~mm}$ (mean $14.7 \mathrm{~mm} \pm 1.9 \mathrm{~mm}$ ) with

Table 5 Laboratory response based on WBC count

\begin{tabular}{llll}
\hline WBC count before and after embolization $\left(\times 10^{\mathbf{3}}\right)$ & \\
\hline & Range & Mean \pm SD & $\boldsymbol{P}$ value \\
\hline Pre embolization & $2.5-3.9$ & $3.3 \pm 0.4$ & \\
1 month post-embolization & $3.5-9$ & $5.4 \pm 1.4$ & $<0.001^{*}$ \\
3 months post-embolization & $4-7$ & $5.5 \pm 1$ & $<0.001^{*}$ \\
6 months post-embolization & $3.5-6$ & $5.3 \pm 0.8$ & $<0.001^{*}$ \\
\hline
\end{tabular}


Table 6 Splenic size changes pre- and post-embolization

\begin{tabular}{llll}
\hline \multicolumn{4}{l}{ Splenic size before and after embolization $(\mathrm{cm})$} \\
& Range & Mean \pm SD & $\boldsymbol{P}$ value \\
\hline Pre-embolization & $14.3-22$ & $17.8 \pm 2.1$ & \\
1 month post-embolization & $14-20$ & $16.7 \pm 1.8$ & $<0.001^{*}$ \\
3 months post-embolization & $13-19$ & $15.6 \pm 1.8$ & $<0.001^{*}$ \\
6 months post-embolization & $12.5-17$ & $14.6 \pm 1.4$ & $<0.001^{*}$ \\
\hline
\end{tabular}

$P$ value $(<0.001)$. Three patients had minimal ascites. Five patients had a recent history of upper GIT endoscopy and local control of esophageal varices (Table 2).

Platelets were the first blood element to be corrected at the early post-embolization period; it was the most reliable indicator for technical success. Comparison of the mean platelet count at the pre-operative laboratory was $34.9 \pm 10.3 \times 10^{3}$, then corrected to $137.6 \pm 37.1 \times 10^{3}$ within 1 month follow-up duration, and then there were some fluctuations at 3- and 6-month follow-up periods; most results were ranking in the figures of around $140 \times$ $10^{3}$ with $P$ value $(<0.001)$ (Table 3$)$.

In $\mathrm{RBCs}$, the mean was $3.6 \pm 0.3 \times 10^{6}$ compared with $4 \pm 0.5 \times 10^{6}$ at 1 month follow-up period, with slight steady elevation during 3- and 6-month durations. WBCs also showed correction at the early post-operative period, $3.3 \pm 0.4 \times 10^{3}$, compared to $5.4 \pm 1.4 \times 10^{3}$ at 1 month, with no significant rise at the late 3rd and 6th month follow-up periods which persists at $5.3 \pm 0.8 \times$ $10^{3}$ with $P$ value $(<0.001)$ (Tables 4 and 5 ).

Preoperative splenic size was ranged from 14.3 to $22 \mathrm{~cm}$ with the mean $=17.8 \pm 2.1 \mathrm{~cm}$ with $P$ value $<0.001$; also, splenic artery and its branches as well as collateral circulation (lienorenal and gastric) were mapped and studied to pre-plane for the procedure itself to avoid the possibility of non-target embolization. Variable degrees of splenic parenchymal infarctions were achieved in the early postembolization period, monitored by abdominal CT scans; by the time of 1 month, we started to notice mild reduction in splenic size, which ranged $14-20 \mathrm{~cm}(16.7 \pm 1.8)$.

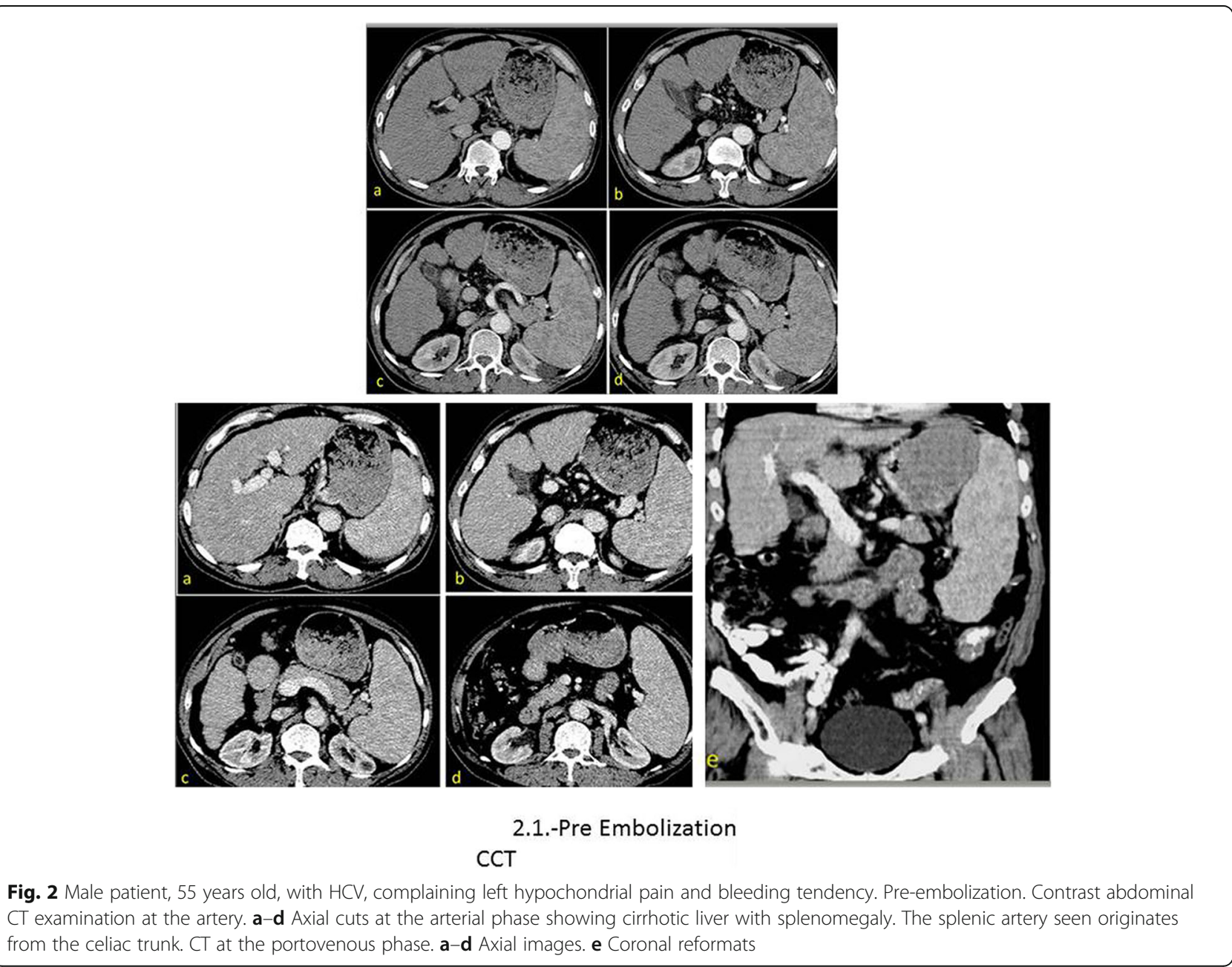




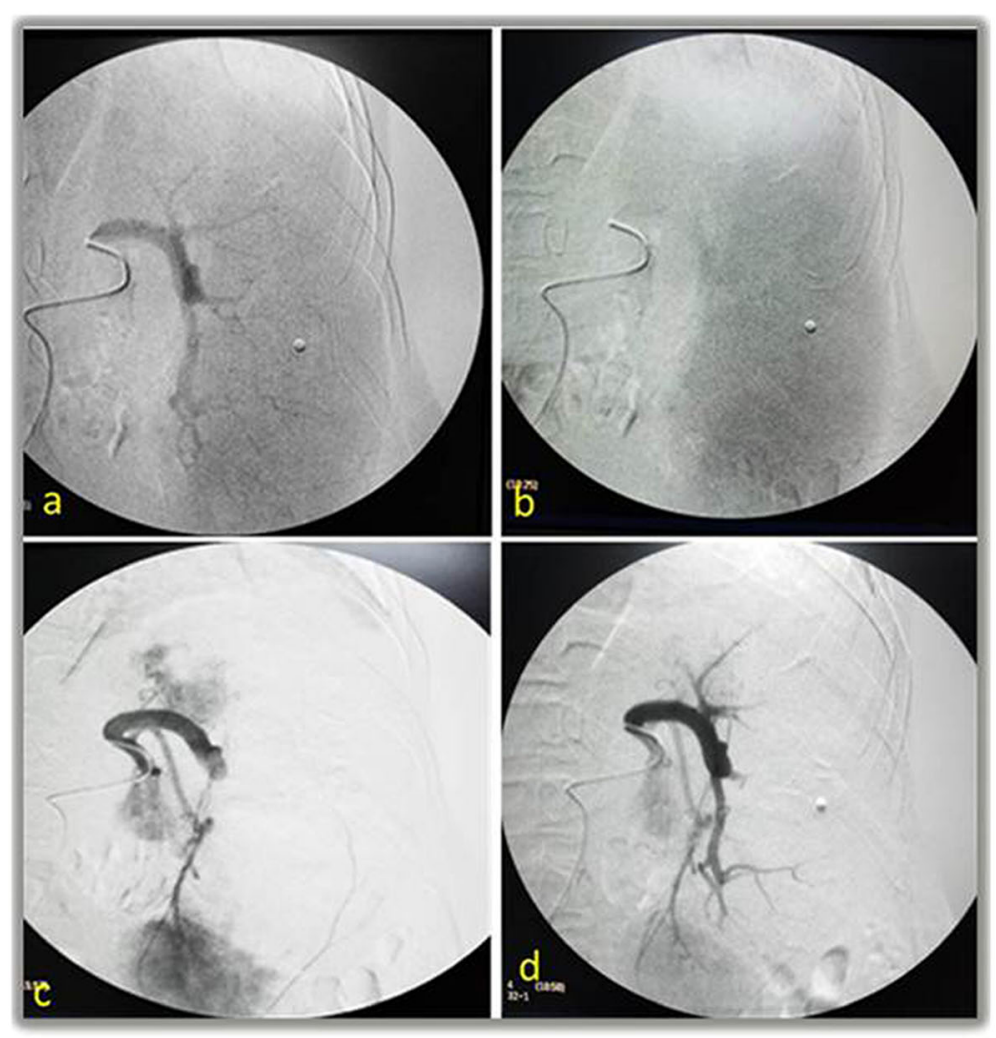

\subsection{PS Embolization}

Fig. 3 PSE. DSA pre- and post-embolization. a, b Selective DSA of splenic artery before embolization showing enlarged spleen with diffuse homogeneous contrast enhancement of splenic parenchyma. c, d Digital subtraction splenic angiography post-embolization showing areas of splenic infarctions about (70\%) with sparing of areas near the splenic hilum

Progressive reduction in size also was achieved by 3 and 6 months follow-up which were $13-19 \mathrm{~cm}(15.6 \pm 1.8)$ and 12.5-17 cm (14.6 \pm 1.4 ) respectively (Table 6) (Figs.2, 3, 4, $5,6,7,8,9,10,11,12$, and 13$)$.

Partial splenic artery embolization like any endovascular procedures is not absolutely safe procedure; it has its own complications; all complications in our study were in the acceptable range with no deaths recorded. All patients $(100 \%)$ had post-embolization syndrome in the form general weakness, fatigue, pain, vomiting, and fever. Twenty percent of patients developed ascites late within the first month of follow-up and persists up to 3 months. Infection was encountered only in two patients. Portal and splenic vein thrombosis was encountered in four patients at the early post-operative period. Mild encephalopathy was seen only in three patients; all were attributed to the Child-Pugh class of the patient at time of the procedure (all were Child-P class B). One uncommon complication happened among the patients; the patient developed ascites, fever, and mild encephalopathy and was diagnosed as spontaneous bacterial peritonitis and treated by antibiotics. No abscess formation could be seen among the treated patients even at the late follow-up periods. No splenic rupture could be seen in all patients (Table 7).

Gelfoam pledges are most widely used based on the splenic sinusoids which can accommodate a large amount of PVA or Embosphere which are very expensive. In the study, Gelfoam was used in 20 patients (66.7\% of cases), while PVA was used in 5 cases (16.66\%), and microspheres were also used 5 patients (16.66\% of cases). We noticed no significant postembolization differences in imaging among the patients with different types of embolizing materials (Table 8).

Antiviral treatment regimen was started after an adequate rise in corpuscular counts in all patients (Table 9).

\section{Discussion}

Egypt has been reported as having the highest prevalence rate of $\mathrm{HCV}$ worldwide, with $\mathrm{HCV}$ antibodies. In turn, the reported incidence of hypersplenism in chronic liver diseases was reported as high as $68 \%$ [10]. 

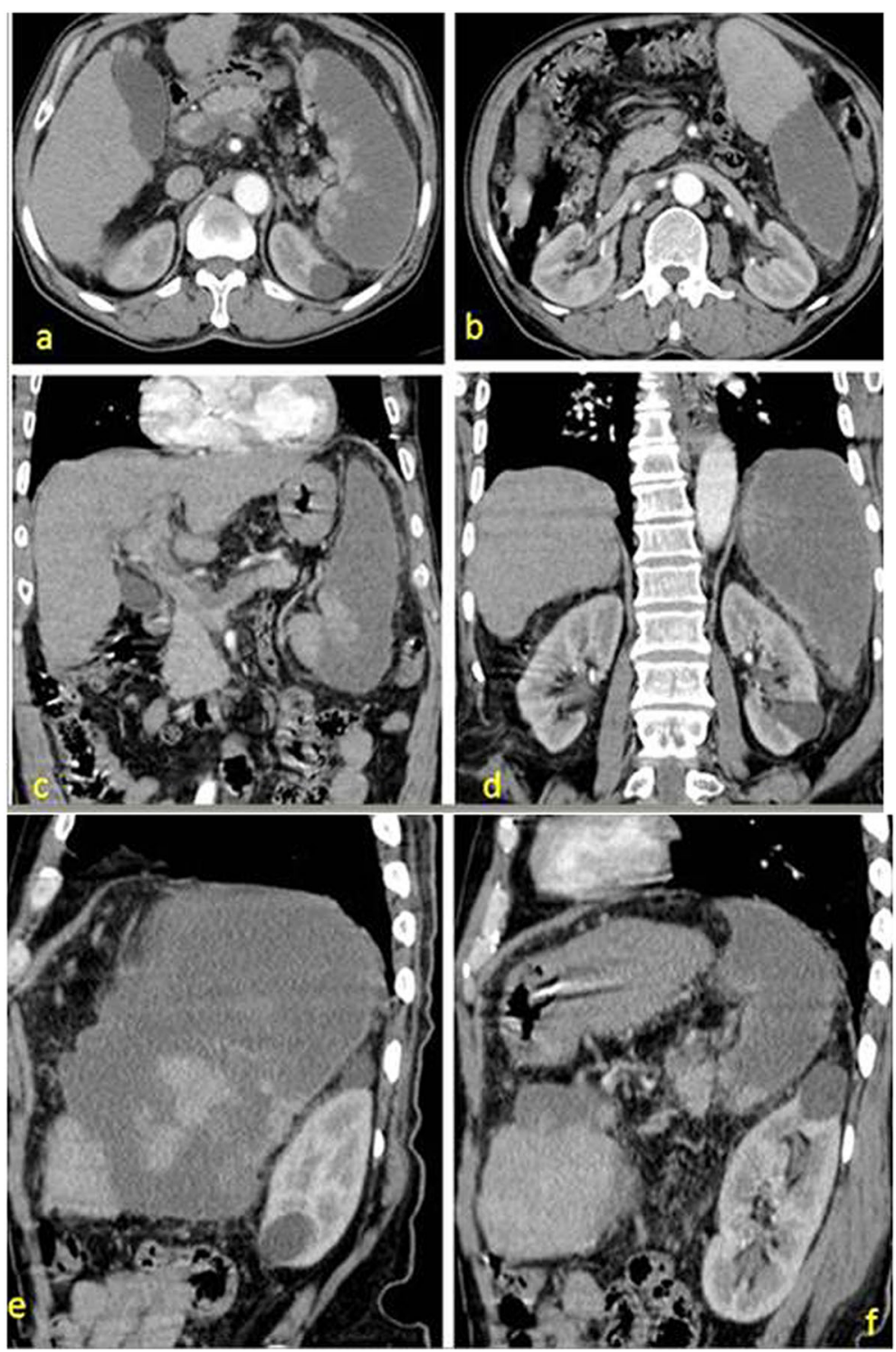

2.3.Post Embolization follow up CT

Fig. 4 Post-PSE. Follow-up abdominal CT examination (3 months) post-splenic embolization. a, b Axial images showing multiple hypodense nonenhanced areas of infarctions seen involving most of the splenic parenchyma with some areas spared. $\mathbf{c}-\mathbf{f}$ Coronal and sagittal reformatted images showed the extent of infarction

With the development of interventional radiology, partial splenic embolization has been widely applied in clinical treatment of hypersplenism especially in patient prepared to antiviral therapy. PSE has fewer risks compared with surgery, shorter hospital stays, and better clinical effects. The open or laparoscopic splenectomy was the cornerstone to treat hypersplenism. However, there are certain limitations and contraindications, like those patients with advanced liver disease associated with considerable morbidity and mortality [11].

In this study, all patients were treated by partial splenic artery embolization with preservation of a part of the splenic tissue with no specific predilection to a certain embolizing material to do this mission, either temporary occluding materials like Gelfoam pledgets or permanent embolizing particles like microspheres and 

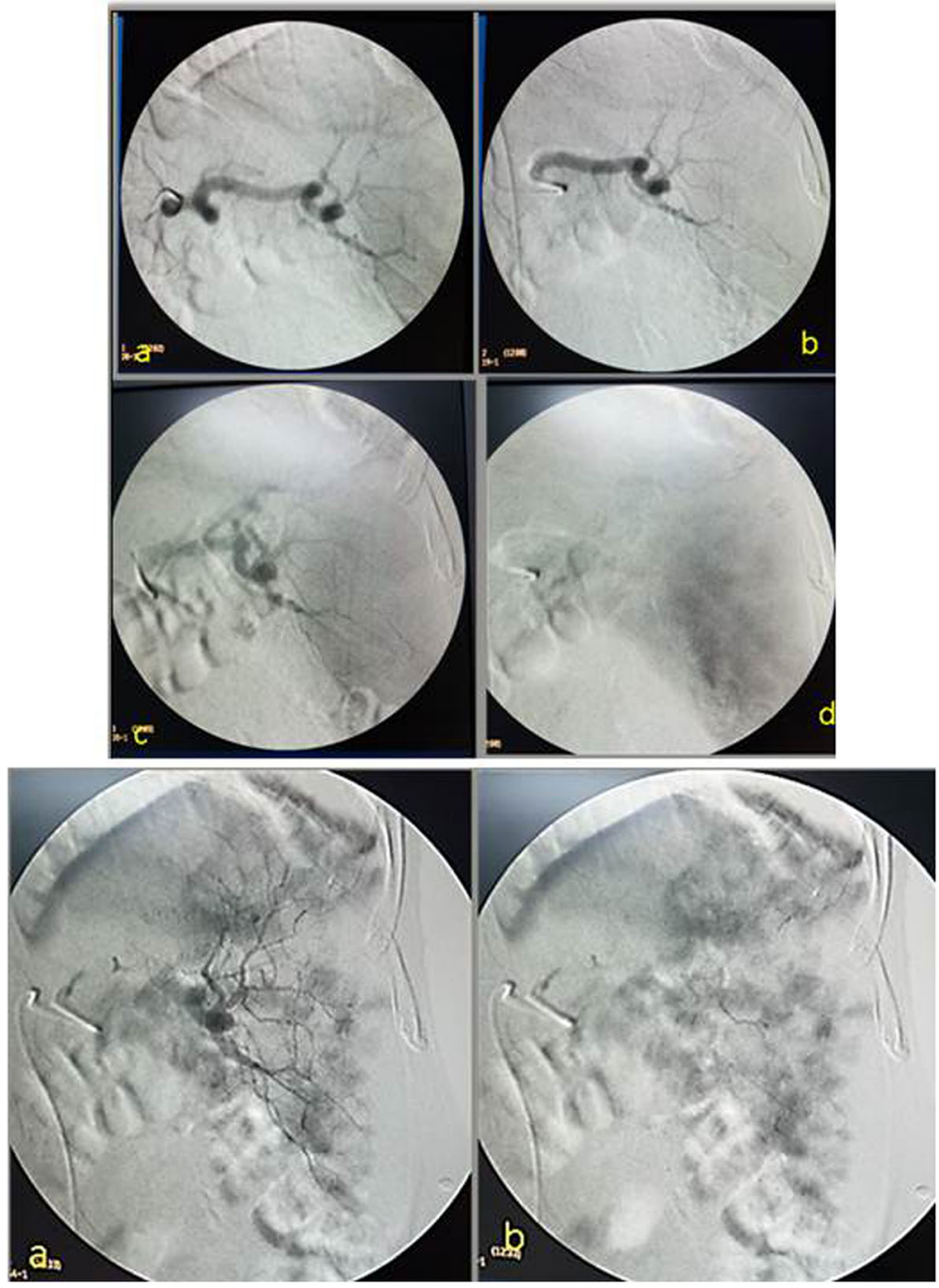

\subsection{PS Embolization}

Fig. 5 Male patient, 57 years old, with thrombocytopenia corrected only by fresh frozen plasma transfusion. a, b Selective DSA of splenic artery before embolization showing splenic artery and its segmental divisions. c, d Delayed images showed the parenchymal phase. DSA postembolization. a, b Multiple areas of splenic infarctions about (70\%) of the splenic parenchyma

PVA; all induced tissue ischemia and infarction with subsequent corpuscular correction. The widely available and cheap Gelfoam particles was the dominant embolizing material $(66.7 \%)$; all of the patients were treated effectively, $16.6 \%$ by microspheres and also $16.66 \%$ by PVA. This agrees with Hickman et al. [6] who successfully used gelatin sponge pledgets and polyvinyl alcohol particles as embolizing materials.

Absorbable gelatin sponge (Gelfoam) is the most commonly described embolic material for partial splenic embolization, but it has been criticized, predominantly because of its temporary nature, but the short time needed for tissue destruction with subsequent irreversible damage of splenic tissue made Gelfoam particles to be enough for this mission [12].

No significant impact on the extent of infarction or the end point results was attributed to the type of the particles used; this agrees with Hayashi et al. [13] who used in their study Gelfoam as the embolizing material, with the therapeutic endpoint being a splenic infarction rate of $70-80 \%$. Different results were observed in the study by Zhu et al. [14]; he reported that PSE using Gelfoam particles or using PVA particles revealed good short- and long-term efficacy in relieving leukocytopenia and thrombocytopenia caused by hypersplenism, but the improvement in WBC and PLT counts was obviously 


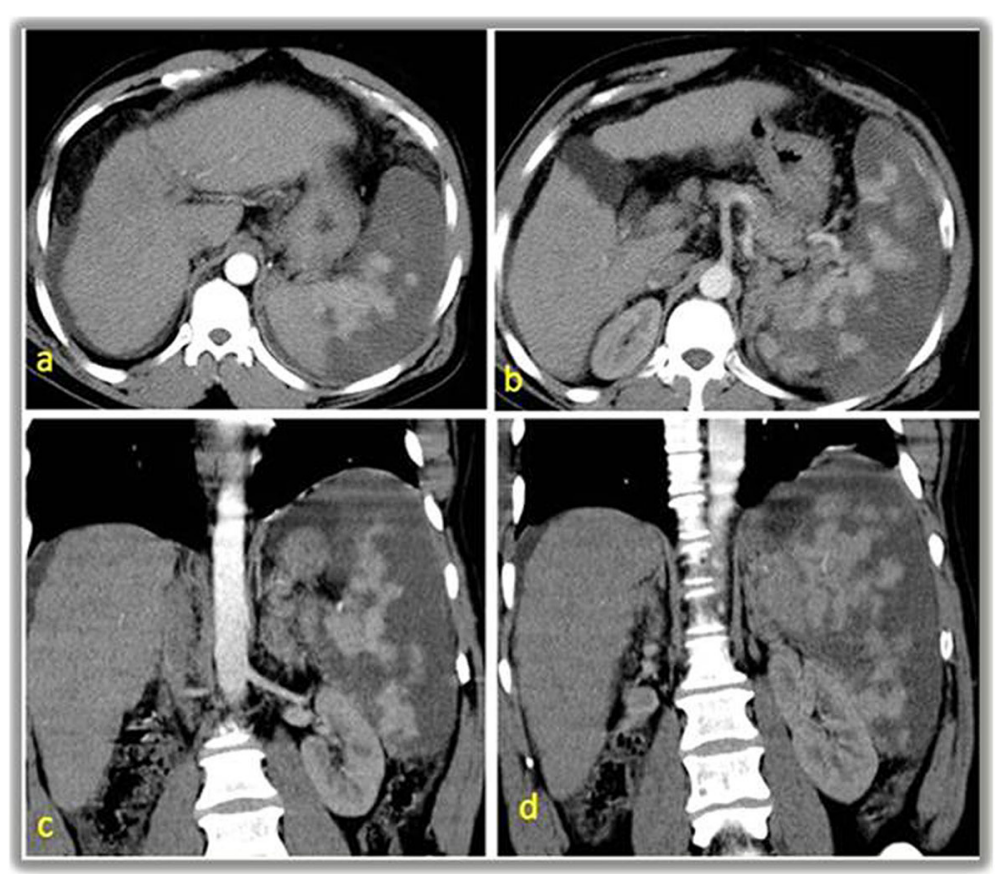

\subsection{Post Embolization follow up}

Fig. 6 Follow-up abdominal CT late arterial phase. a, b Axial images. c, d Multiplanar coronal reformatted images. Multiple large well-defined non-enhanced geographically distributed hypodense areas involving most of the splenic parenchyma (about 70\%) with other smaller normally perfused areas enhanced with contrast material, denoting residual variable splenic tissue after embolization

better in the PVA group than in Gelfoam. Petermann et al. [15] concluded that effective splenic artery embolization for hypersplenism due to portal hypertension requires embolization of more than $50 \%$ of the parenchyma.

Pre-embolization mean platelet count was $34.9 \pm 10.3$ $\times 10^{3}$ that was corrected up to $137.6 \pm 37.1 \times 10^{3}$ within 1 month follow-up duration, which then showed some fluctuations at 3- and 6-month follow-up periods. There was some unexplained relapse of few cases that necessitated more treatment sessions. The results of our study revealed that PSE was a highly effective treatment in improving thrombocytopenia in patients with hypersplenism who started antiviral region after correction. Platelets were the first to be corrected at the early post-embolization period and as indicator for technical

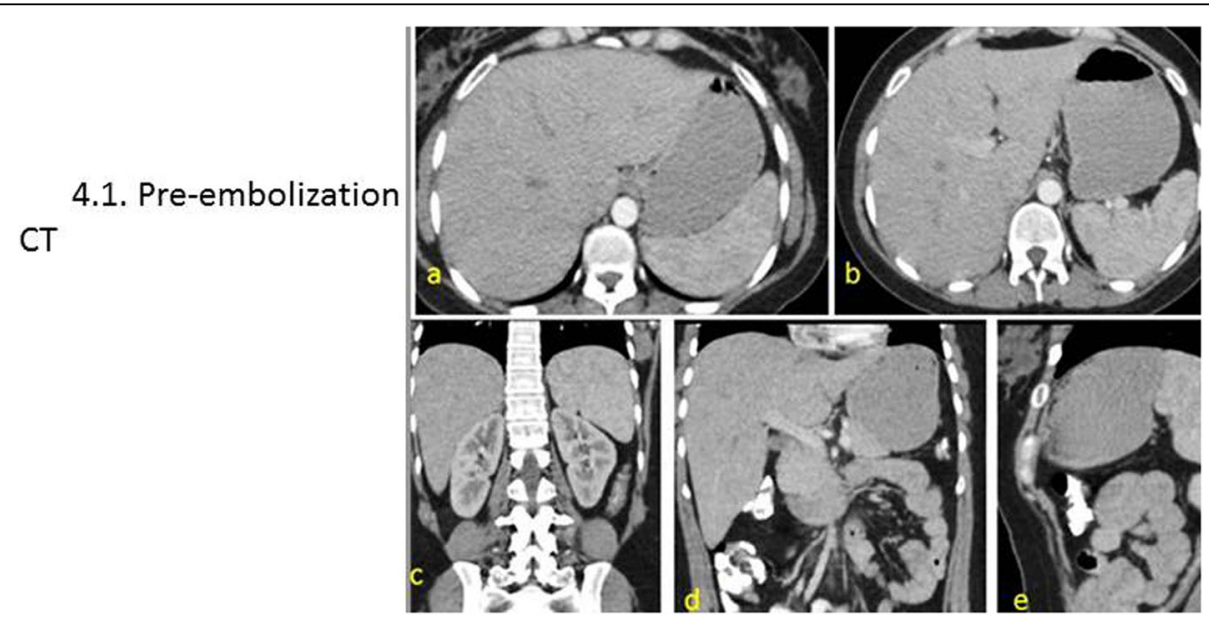

Fig. 7 Female patient, 45 years old, complaining of bleeding tendency and anemic manifestations. Pre embolization CT. Abdominal multislice CT examination post-contrast study. a, b Axial images. c, d Coronal images. e Sagittal images at the portovenous phase showing mild hepatosplenomegaly 

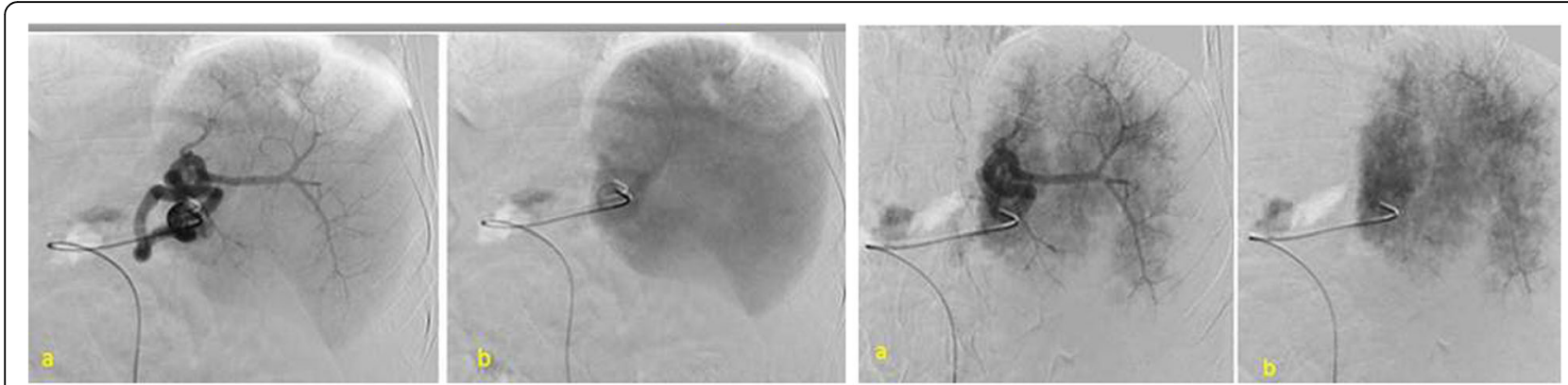

\subsection{PS Embolization}

Fig. 8 PSE. Selective digital subtraction splenic angiography. a, b DSA of the splenic artery showing the tortuous splenic artery. The tip of the catheter reaching as distal as possible nears the splenic hilum. DSA. $\mathbf{a}, \mathbf{b}$ Splenic angiography post-embolization showing multiple areas of splenic infarctions (mainly peripherally located) representing about $50 \%$ of the splenic parenchyma

success. This runs close to the results reported by Zhu et al. [14] who found that the pre-embolization platelet count was $44.36 \pm 16.67 \times 10^{3}$, which then after 1 month became $125.36 \pm 23.25 \times 10^{3}$ and 6 months post-procedural became $111 \pm 18.76 \times 10^{3}$.

The ideal extent of splenic parenchymal infarction for the improvement in hematologic values remains unknown [16]. In our study, $50-70 \%$ embolization area is effective in the improvement of thrombocytopenia and leukocytopenia. Sangro et al. [17] noted that less than $50 \%$ splenic infarction was associated with a poor hematologic response but that $60-70 \%$ infarction was associated with more durable and substantial improvement in hematologic values.

Based on the amount of induced tissue infarction, a lot of studies attributed the variation of platelet count postembolization matches the percentage of infarction which was $50-70 \%$ of splenic tissue in our study compared with that reported by Lee et al. [18] who observed a marked variation of platelet value between his study groups (low group; 30\% embolization) and high embolization group (70\% embolization). In another study by Ganesh et al. [19], the authors demonstrated that $65-70 \%$ embolization area is effective in platelet

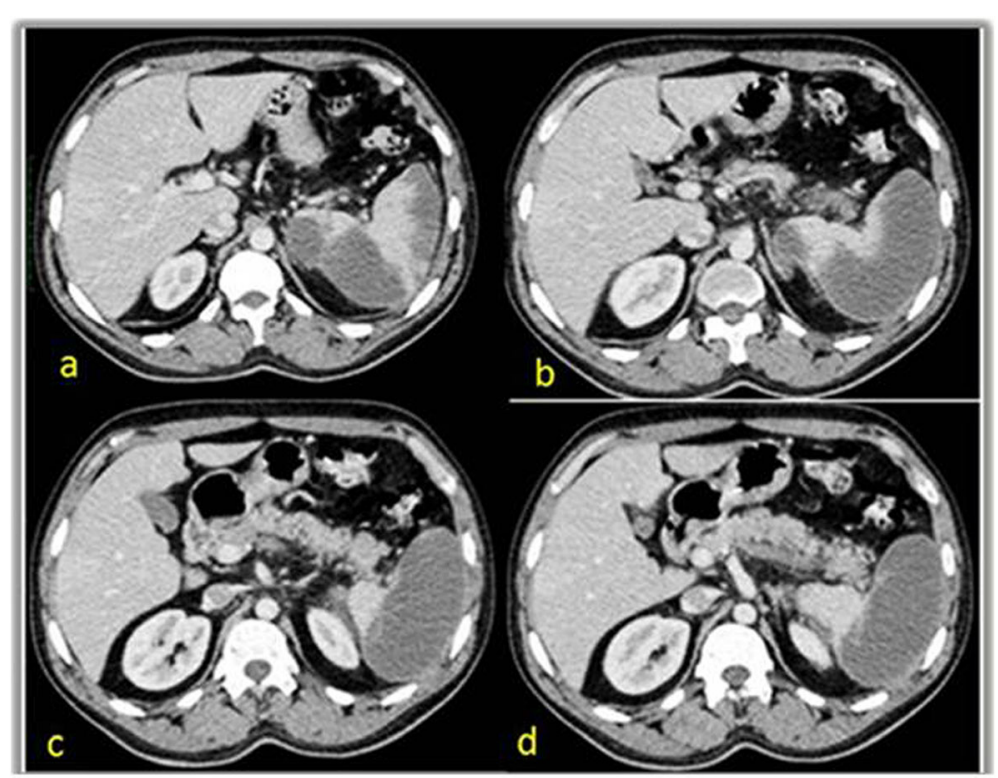

4.3. Post Embolization follow up CT

Fig. 9 Post-embolization follow-up CT examination. a-d Multiple axial cuts at the portovenous phase revealed multiple hypodense areas of near fluid density seen involving most of splenic parenchyma with mainly peripheral distribution, denoting post-embolization multiple infarctions 

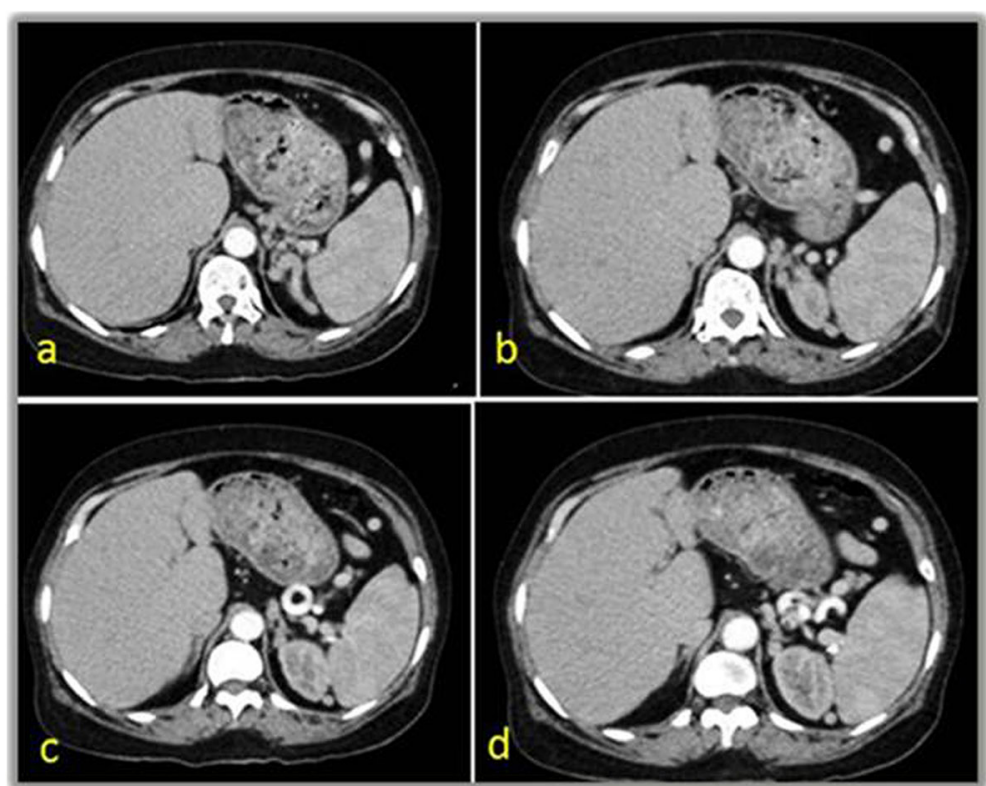

\subsection{Pre-embolization CT}

Fig. 10 Female patient, 48 years old, with chronic HCV, referred for correction of thrombocytopenia. Pre-embolization post-contrast CT examination. a-d Axial images at the arterial phase showing diffuse hepatic disease with mild splenomegaly. e, $\mathbf{f}$ Multiplanar reformatted coronal and sagittal images at the portovenous phase confirming presence of mild splenomegaly

5.2. PSE procedure
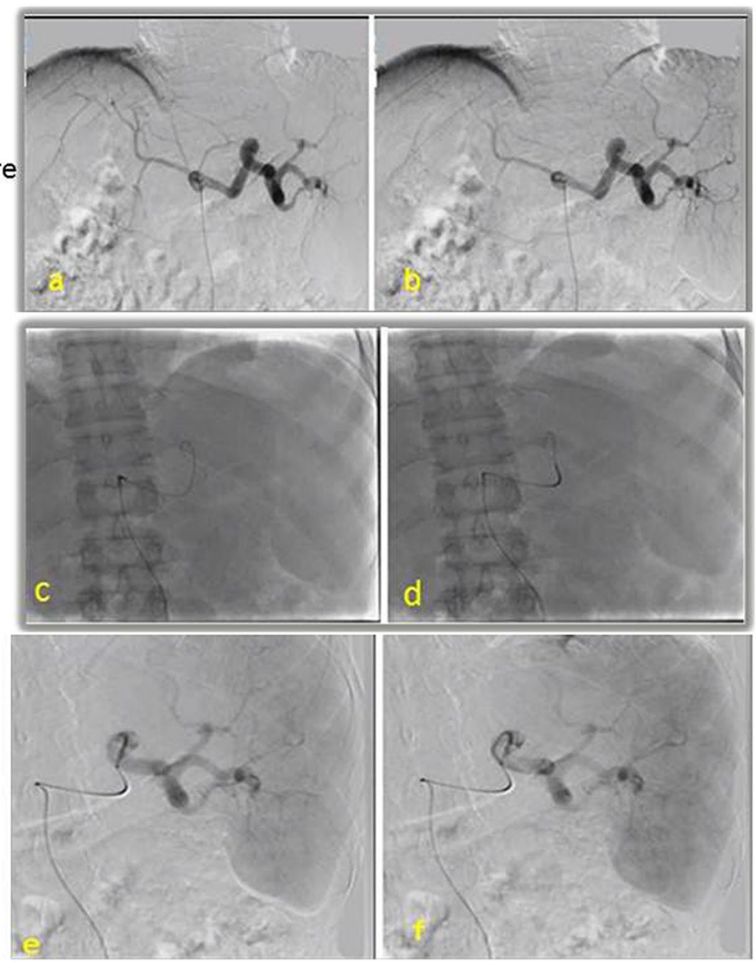

Fig. 11 Embolization procedure DSA of the celiac trunk and splenic artery before embolization. a, b The origin of splenic artery. Images showing both guide wide and cobra catheter advancement proximally within splenic artery. Selective splenic artery angiographic images showed segmental branches of the splenic artery with no pancreatic or gastric branches denoting very good position for embolization. Post-embolization angiography. a, b Splenic angiography after the beginning of the embolization showing insufficient embolized areas 


\subsection{Post embolization}
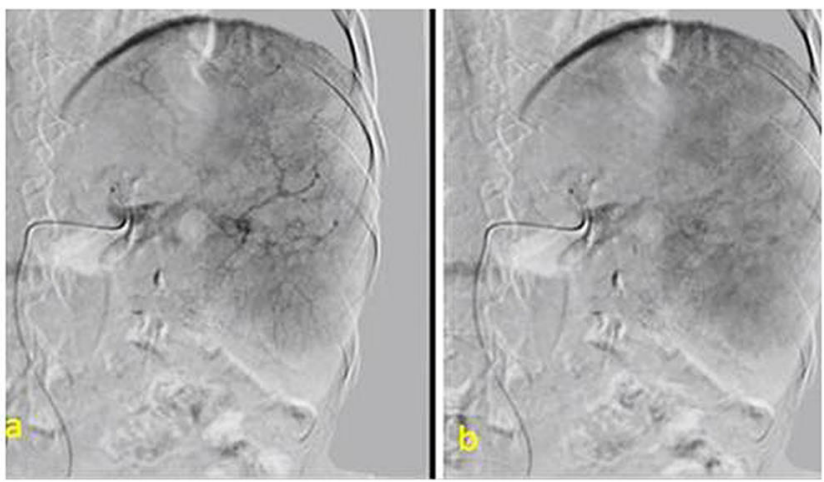

Fig. 12 Angiography after injection of more embolizing material for achieving 50\% embolization

value improvement in liver cirrhosis patients with thrombocytopenia.

The post-embolization improvement in WBC count agreed with Palsson et al. [20], who estimated long-term leucocytes values after PSE; the mean WBC count was 8 $\times 10^{3} / \mu \mathrm{L}$. RBCs also showed significant change after PSE with slight steady elevation during 3 and 6 month's duration $\left(4.4 \pm 0.5 \times 10^{6} / \mu \mathrm{L}\right)$. This disagrees with what was found in a study done by Zhu et al. [14] who noticed no significant elevation of the RBC count which was $3.24 \pm$ $0.57 \times 10^{6} / \mu \mathrm{L}$ before the procedure which became 3.33 $\pm 0.59 \times 10^{6} / \mu \mathrm{L}$ after 6 months.

The pre-embolization mean splenic size in our study was $17.8 \pm 2.1 \mathrm{~cm}$, which reached $16.7 \pm 1.8 \mathrm{~cm}$ after 1 month. Three months post-procedural, it was $15.6 \pm 1.8$ $\mathrm{cm}$; however, by the end of 6 months, it was $14.6 \pm 1.4$ $\mathrm{cm}$. He Xin-Hong et al. [21] found that splenic volume decreased significantly post-embolization 1 month after the procedures, and then gradually increased during the 4-year follow-up.

Significant decrease in portal vein diameter and portal venous pressure was achieved in this study. This agrees with the results of Nishida et al. [22] that found a drop in portal venous pressure after transient splenic artery occlusion.

Most of the complications encountered in our study were in the accepted range and secondary to tissue destruction and ischemia; post-embolization syndrome was the most common complication and occurred in almost all patients (100\%). This agreed with Zhu et al. [14] who found that post-embolization syndrome was the most frequent side effect.

The limitations of this study include a small sample size, single-center data collection, and non-randomized

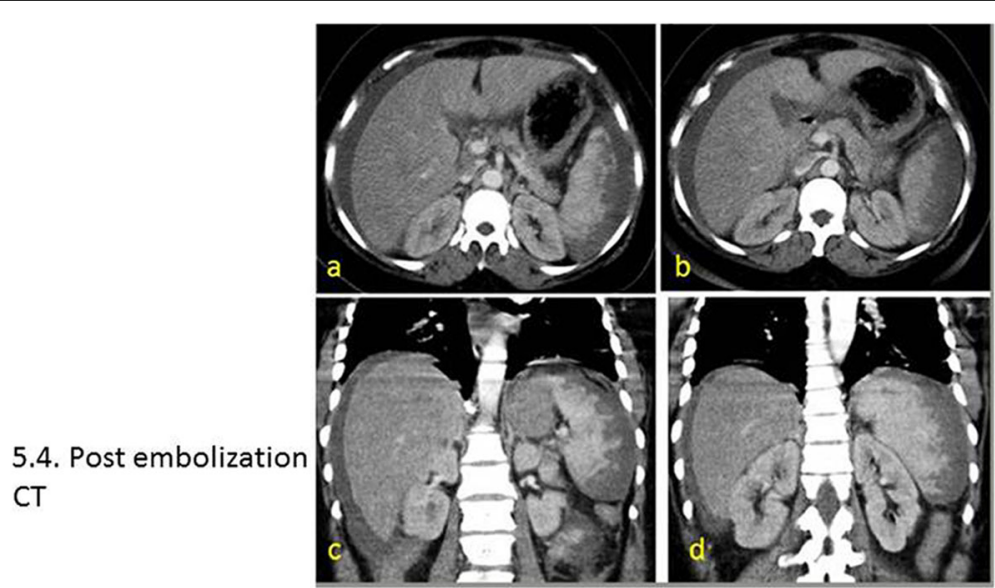

Fig. 13 Multislice $C T$ study of the abdomen at the post-contrast phase. a, b Axial images. $\mathbf{c}$, d Coronal reformatted images showing multiple peripherally located hypodense areas of splenic infarctions 
Table 7 PV diameter pre- and post-embolization

\begin{tabular}{llll}
\hline PV diameter before and after embolization $(\mathrm{mm})$ & & \\
\hline & Range & Mean \pm SD & $\boldsymbol{P \text { value }}$ \\
\hline Pre embolization & $11-18$ & $14.7 \pm 1.9$ & \\
1 month post-embolization & $11-16$ & $13.6 \pm 1.5$ & $<0.001^{*}$ \\
3 months post-embolization & $12-15.5$ & $12.9 \pm 0.9$ & $<0.001^{*}$ \\
6 months post-embolization & $12-15$ & $12.6 \pm 0.6$ & $<0.001^{*}$ \\
\hline
\end{tabular}

Table 8 Post-procedure complications in the study group

\begin{tabular}{llll}
\hline Complications & & $\begin{array}{l}\text { Number of } \\
\text { patients }\end{array}$ & $\begin{array}{l}\text { Percentage } \\
(\%)\end{array}$ \\
\hline $\begin{array}{l}\text { 1- Minor } \\
\text { complications }\end{array}$ & $\begin{array}{l}\text { Post-embolization } \\
\text { syndrome }\end{array}$ & 30 & 100 \\
& $\begin{array}{l}\text { Ascites } \\
\text { Pneumonia }\end{array}$ & 6 & 20 \\
& PV thrombosis & 1 & 6.7 \\
& SV thrombosis & 3 & 3.3 \\
\multirow{2}{*}{ 2- Major } & Encephalopathy & 3 & 10 \\
& $\begin{array}{l}\text { Spontaneous bacterial } \\
\text { peritonitis }\end{array}$ & 1 & 10 \\
& $\begin{array}{l}\text { Splenic abscess or } \\
\text { rupture }\end{array}$ & 0 & 3.3 \\
& & & 0 \\
&
\end{tabular}

Table 9 Type of embolizing materials used in different patients

\begin{tabular}{lll}
\hline Embolizing materials & Number & Percentage (\%) \\
\hline 1- Temporary (Gelfoam) & 20 & 66.7 \\
2- Permanent & & \\
$\quad$ Polyvinyl alcohol (PVA) & 5 & 16.66 \\
Microspheres (Embospheres) & 5 & 16.66 \\
\hline
\end{tabular}

design. The long duration of enrollment and prolonged follow-up of patients are the major strengths of our study.

\section{Conclusion}

Partial splenic artery embolization is an effective alternative method to surgery in treatment of hypersplenism particularly in cirrhotic patients prepared for antiviral treatment with correction of the associated thrombocytopenia.

\section{Abbreviations}

Child-P grade: Child-Pugh grade; GM-CSF: Granulocyte-macrophage colonystimulating factor; PSE: Partial splenic artery embolization; PVA: Polyvinyl alcohol; TIPS: Transjugular intrahepatic portosystemic shunt; Y-90: Yttrium-90

\section{Acknowledgements}

To my god I am gratefully indebted; nothing can be done without him.

\section{Authors' contributions}

All authors read and approved the final manuscript. ME: Interventional technique, image interpretation. MAS: Interventional techniques, follow-up, and laboratory data. NO: Sharing in technique, image interpretation, revision, and final editing.

\section{Funding}

No funding was received for this work from any organization.

\section{Availability of data and materials}

The datasets used and/or analyzed during the current study are available from the corresponding author on reasonable request.

\section{Ethics approval and consent to participate}

This study was approved by the ethics committee of the Faculty of Medicine, Minya University (the reference number is not applicable now), and consent to participate was taken by the authors.

\section{Consent for publication}

All patients included in this study gave written informed consent to participate in this research.

\section{Competing interests}

The authors declare that they have no competing interests.

Received: 2 April 2020 Accepted: 9 August 2020

Published online: 25 August 2020

\section{References}

1. Shah SH, Hayes PC, Allan PL (1996) Measurement of spleen size and its relation to hypersplenism and portal hemodynamics in portal hypertension due to hepatic cirrhosis. Am J Gastroenterol 91:2580-2583

2. Peck-Radosavljevic M (2001) Hypersplenism. Eur J Gastroenterol Hepatol 13: 317-323

3. Madoff DC, Denys A, Wallace MJ et al (2005) Splenic arterial interventions: anatomy, indications, technical considerations, and potential complications. RadioGraphics 25:S191-S211

4. Athale UH, Kaste SC, Bodner SM et al (2000) Splenic rupture in children with hematologic malignancies. Cancer 88:480-490

5. Liangpunsakul S, Ulmer B, Chalasani N (2003) Predictors and implications of severe hypersplenism in patients with cirrhosis. Am J Med Sci 326:111-116

6. Hickman MP, Lucas D, Novak Z et al (1992) Preoperative embolization of the spleen in children with hypersplenism. J Vasc Interv Radiol 3:647-652

7. Tajiri T, Onda M, Yoshida $\mathrm{H}$ et al (2002) Long-term hematological and biochemical effects of partial splenic embolization in hepatic cirrhosis. Hepatogastroenterology 49:1445-1448

8. Kimura F, Ito H, Shimizu H et al (2003) Partial splenic embolization for the treatment of hereditary spherocytosis. AJR 181:1021-1024

9. Hong Y, Hwa-Koon W, Yancg AD et al (1999) Evaluation of partial splenic embolization in patients with hypersplenism in cirrhosis. Chin J Radiol 24(6): 233-237 
10. Ashraf S, Naeem S (2010) Frequency of hypersplenism in chronic liver disease patients presenting with pancytopenia. Spec Ed Ann 16:1

11. Ferraz AA, Bacelar TS, Silveira MJ et al (2001) Surgical treatment of schistosomal portal hypertension. Int Surg 86:1-8

12. Gonsalves CF, Mitchell EP, Brown DB (2010) Management of hypersplenism by partial splenic embolization with ethylene vinyl alcohol copolymer. AJR 195:1241-1244

13. Hayashi H, Beppu T, Masuda T et al (2007) Predictive factors for platelet increase after partial splenic embolization in liver cirrhosis patients. Journal of gastroenterology and Hepatology 22:1638-1642

14. Zhu K, Meng X, Li Z et al (2008) Partial splenic embolization using polyvinyl alcohol particles for hypersplenism in cirrhosis: a prospective randomized study. European Journal of Radiology 66:100-106

15. Petermann A, Chabrot P, Cassagnes $L$ et al (2012) Hypersplenism due to portal hypertension: retrospective evaluation of 17 patients treated by splenic embolization. Diagnostic and Interventional Imaging 93:30-36

16. Koconis KG, Singh H, Soares $G$ (2007) Partial splenic embolization in the treatment of patients with portal hypertension: a review of the English language literature. J Vasc Interv Radiol 18:463-481

17. Sangro B, Bilbao I, Herrero I et al (1993) Partial splenic embolization for the treatment of hypersplenism in cirrhosis. Hepatology 18:309-314

18. Lee C, Leung T, Wang $\mathrm{H}$ et al (2007) Evaluation of the effect of partial splenic embolization on platelet values for liver cirrhosis patients with thrombocytopenia. World J Gastroenterol 13:619-622

19. Ganesh A, Rose JB, Maxwell LG (2005) Protracted pain following partial splenic embolization in an adolescent female with hypersplenism. Pediatric Anaesth 15:1013-1015

20. Palsson B, Hallen M, Forsberg A et al (2003) Partial splenic embolization: long term outcome. Langenbecks Arch Surg 387:421-426

21. He X-H, Jian-Jian G, Wen-Tao L et al (2012) Comparison of total splenic artery embolization and partial splenic embolization for hypersplenism. World J Gastroenterol 18(24):3138-3144

22. Nishida O, Moriyasu F, Nakamura T et al (1987) Interrelationship between splenic and superior mesenteric venous circulation manifested by transient splenic arterial occlusion using a balloon catheter. Hepatology 7:442-446

\section{Publisher's Note}

Springer Nature remains neutral with regard to jurisdictional claims in published maps and institutional affiliations.

\section{Submit your manuscript to a SpringerOpen ${ }^{\circ}$ journal and benefit from:}

- Convenient online submission

- Rigorous peer review

- Open access: articles freely available online

High visibility within the field

- Retaining the copyright to your article

Submit your next manuscript at $\boldsymbol{\nabla}$ springeropen.com 